\title{
The Theatre and its Screen Double
}

\author{
Johannes Birringer
}

If I were to say "alles weitere kennen Sie aus dem Kino" (the rest will be familiar to you from the movies), I would probably promise too much, or too little, depending on your preference for live theatre or performance art, the latter priding itself for the longest time on an intrinsic resistance to mediatization. The cinema's relationship to theatre has of course evolved through several stages. It may have been one of "creative destruction" ever since the younger medium's inception at the end of the nineteenth century, as the editors of Against Theatre argue, but early modern cinema developed its formal means as an aesthetically distinct medium not only by denying a dependency on theatricality. It also borrowed from theatrical aesthetics, acting styles, and conventions of both realism and anti-illusionism before refining its crucial resources of shot scale, mobile framing, camera angles and editing, its wide range of rhythmic cutting patterns and close-ups.(1) The paradoxical boundary relations between cinema and stage continue to be intimately dynamic throughout the later twentienth century, and the mutual adaptations or conversions of techniques, framing devices, spatio-temporal properties etc. would require very careful delineation if one were to eager to detect anything like an anti-cinematic prejudice in mainstream western theatre. An insistence on live presence and the uniquely ephemeral was provocatively argued, however, by Peggy Phelan's wellknown exposé on the "ontology of performance;" the counter-argument regarding mediatization and reproduction obviously gained ground as the cultural economy of the digital gradually established the overriding presence of media technologies in all areas: the digital incorporates performance, and performance already knows - and is received by audiences in this manner - that its remix and reactivation is inevitable.(2) Less concerned with the issue of recording and documentation as such, I wonder how the presence of filming-on-stage produces (or not) familiar effects of the movies.

If the theatre held out a promise of the not yet all too familiar rest, how do we value its visceral matter, plasticity and spatial poetry, its bodies on stage, its expenditure of energies and the "wholly materialized gravity" Artaud defended ecstatically when he described the 
Balinese dance (rather than Western masterpieces) in The Theatre and its Double?(3) How do we value its embodiment when we watch its artificial construction on stage? It is still fascinating to read Artaud today and ponder his comments on "spatial density" and his dismissal of the "stammering" he associates with spoken theatrical language and dialogue.(4) In his "Theatre and Cruelty," bemoaning the loss of the idea of theatre, Artaud adds: "Cinema, in its turn, murders us with reflected, filtered, and projected images that no longer connect with our sensibility, and for ten years has maintained us and our faculties in an intellectual stupor."(5) At an early stage of the history of the movie industry, this critique still comes as a surprise given Artaud's involvement in film projects from the mid-1920s to the mid-1930s. My own interest in the fusions of the digital, cinematic, and theatrical is to some extent inspired by Artaud's original conception of filmic work in immediate contact with the human body - what he called "raw cinema" - as I understand him of course to have been aware that mediation (filtering, projection) is inescapable in film.(6) At the same time, my work as a choreographer on the contemporary digital stage - a realm of real-time interactive processing, computation and the virtual - has made me curious about the strategies of theatre directors who may not primarily compose with movement and the kinetics of captured/processed motion (as pioneered in Lucinda Childs's Dance, 1979, and later shown in dance productions by Merce Cunningham, Bill T. Jones, Dumb Type, Troika Ranch, Klaus Obermaier, Chunky Move, Wayne McGregor and others) but with narrative, language and actors trained in psychological realism.

Looking back over the past twenty years of working in the international dance and technology scene, I have rarely seen an interactive digital dance piece that did not use projected/screenic images on stage. Screens, and what I think of as screenic arrangements, are a fundamental presence in the design. Media output is part and parcel of the aesthetic of composing movement that affects and modulates graphic images and the doubling of movement-figures on screens. Visual interactivity requires an explicit, affective and reciprocal relation between dancer and modulated image. But the architecture of sensing (camera vision and motion capture systems installed on stage or used prior to the live/projected dance) is different from theatre productions I have observed where cameras become actors, so to speak, gaining an unmistakable role in the dramaturgy and participating in the mise en scène, moving around the performance space. This is one of the key differences, say, between Cunningham's BIPED, which features a large open and empty 
stage (using back and front scrim projection of virtual dancers), and Katie Mitchell's live film productions with her densely cluttered stage dispositifs.

What I want to explore in the following case study - Mitchell's adaptation of Strindberg's Fräulein Julie - is the role of camera-as-actor on the theatre stage, and therefore the particular role of such a camera-actor for an adaptation, a re-writing of a play. The presence of film within the theatre has tended to be a minor phenomenon associated with the experimental avant-garde, not with the realist conventions of modern drama on the actor dominated stage and the kind of psychological realism associated with Stanislavski's training methods. Having read about Piscator, Meyerhold, Eisenstein, Tretyakov and Svoboda, my first exposure to this minor "literature" was in New York in the 1980s, watching video/performances created by director-auteurs such as Elizabeth LeCompte (Wooster Group), John Jesurun, or Robert Lepage; and by the 1990s the use of video projection had also become an increasingly frequent feature of the growing dance and technology movement in North America, Japan, and Europe.(7) These directors, along with choreographers deploying kinetic image projection and digital manipulation of captured movement, worked with their own ensembles and were able to develop their own particularized aesthetics and staging techniques. Mitchell seems surprised when she is asked whether she considers herself an auteur, but comments eloquently in several interviews on directing and cinematography in multimedia productions, referring to her recent productions as "camera shows."(8)

When a theatre director, invited by a mainstream venue such as the National Theatre or the Berlin Schaubühne, decides to turn a classic modern play into a "live film" on stage, some rather interesting questions arise regarding, obviously, the directing choices, cinematography, scenography and acting, but also regarding the gradual impact of multimedia decompositions of realism in the wider context of postdramatic performance, effected in the UK for example by companies such as Station House Opera, Theatre Complicité, 1927, Imitating the Dog, or Punchdrunk. In spite of the work of such ensembles, it could be argued that there are no widely established conventions of live cinematography in Western theatre, and thus a given (and limited) range of acting styles or devising techniques may not be transferable to "live film" nor benefit from the promotional protocols of dominant popular-cultural media and camera work (from television shows and advertising commercials to Reality TV, music video, and sports coverage with multiple angles and slow-motion replays). If such conventions were established, it could not be explained why Jay Scheib's Chekhov 
adaptation, Platonov, or The Disinherited, produced at the Kitchen in January 2014, received such curious attention in the New York Times.(9)

Mitchell's directorial work, ever since her productions for the National Theatre in London (e.g. The Waves, 2006; The City, 2007; Women of Troy, 2007; ...some trace of her, 2008; Pains of Youth, 2009; Beauty and the Beast, 2010), invites mainstream audiences to reflect on their spectatorial role and the level of distraction they might experience watching the maneuvering of technological tools on stage, the busy work of Foley artists producing sound effects. Surely any fundamental ideological insistence on the primacy of unmediated performance is put to rest in Mitchell's precise blocking of actors on stage who take shots with cameras and rearrange the lighting for the shots. In the interviews mentioned above, Mitchell speaks of the "ugliness of the chaos of construction," which she seems to enjoy as it is in service of constructing beautiful images, "finding the right image, and then the behavior inside it," as she claims in reference to The Waves and ...some trace of her (the adaptation of Dostoevsky's The Idiot). Among the productions I listed, her Pains of Youth was not a camera show but, as she mentions in the interviews, a "relief" and a return to "straight theatre," working with actors in psychological realism without the chaos.

In the context of postmodern and postdramatic performance, after the recent decades of hybrid experimentation across all media and live art, the defense of the live actor on stage (straight theatre) is not urgent business any longer. After the first video monitors appeared on stage, followed by filmic projections coupled with complex electronic sound effects, we probably should have come to expect that the media might as well be natural dimensions of contemporary stage craft providing a multiplicity of interactions and intermedial play on stage for discerning audiences who have grown up in a culture of remediation. The theatre, to paraphrase Brecht, can remediate anything it likes to; it can in fact foreground and expose its framing devices, it can ambush the repetition of hegemonic representation. The forms of intermedial play, however, are not self-evident, and I therefore suggest to take a closer look at Mitchell's strategies and provide insight into her foregrounding what we may not know from the movies.(10)

Mitchell's version of Strindberg's Fräulein Julie is a good example of an intermedial performance inviting us to watch a play that unfolds on a sound stage as a live filming of an action adapted from a dramatic source - "after Strindberg." Over the past six or seven years, 
after her early deconstructive Seagull production (at the National in 2006) which received a very divisive critical response, Mitchell has continuously elaborated her experiments with film and the effects of filmic technology on her stage choreography; her directorial control over the action on stage appears ever more meticulous. Cameras, camera operators, editors, sound equipment and sound makers have joined actors as performers: the production features nine actors/operators and five cameras in the total synthesis of this composed theatre (just as Wagner had predicted already in the $19^{\text {th }}$ century, however with a focus on music drama). It stops short of going as far as Heiner Goebbels's theatre installation, Stifters Dinge (2007), a "composition for five pianos with no pianists, a play with no actors, a performance without performers, a no-man show," which displaces actors and musicians to draw attention to the synthetic operational assemblage.(11) Brecht's Epic Theatre, based on interruption (and formulated against Wagner's totalization), is also side-stepped, as there is nothing that is ever interrupted in Mitchell's production. But her seamless synthesis bears unconventional features since on the mainstream theatre stage we rarely think of the cameraman or the camera as an actor. I cannot be sure whether the producers think so, either. The photos handed to the press oddly mention only the Schaubühne actors visible in the frame, not the camera operators (also visible), even though the actors (Jule Böwe, Luise Wolfram, Tilman Strauss) themselves would not appear at all on screen without Stefan Kessissoglou and Krzysztof Honowski (camera), and would not be heard without Laura Sundermann and Stefan Nagel (sound).

The three Schaubühne actors, and in addition the silent Kristin double (Cathlen Gawlich) do share the camera work during the performance, and we also see and hear Chloe Miller (cellist) on stage. Adding to the confusion, Kristin's hands on film are credited to sound artist Stefan Nagel and actress Luise Wolfram. Back of the house sound mixing and film editing are done by co-director Leo Warner with Gareth Fry and Adrienne Quartly; additional music is composed by Paul Clark, and lighting designed by Philip Gladwell. The program credits "further camera takes, sounds, and voices" by the ensemble. 


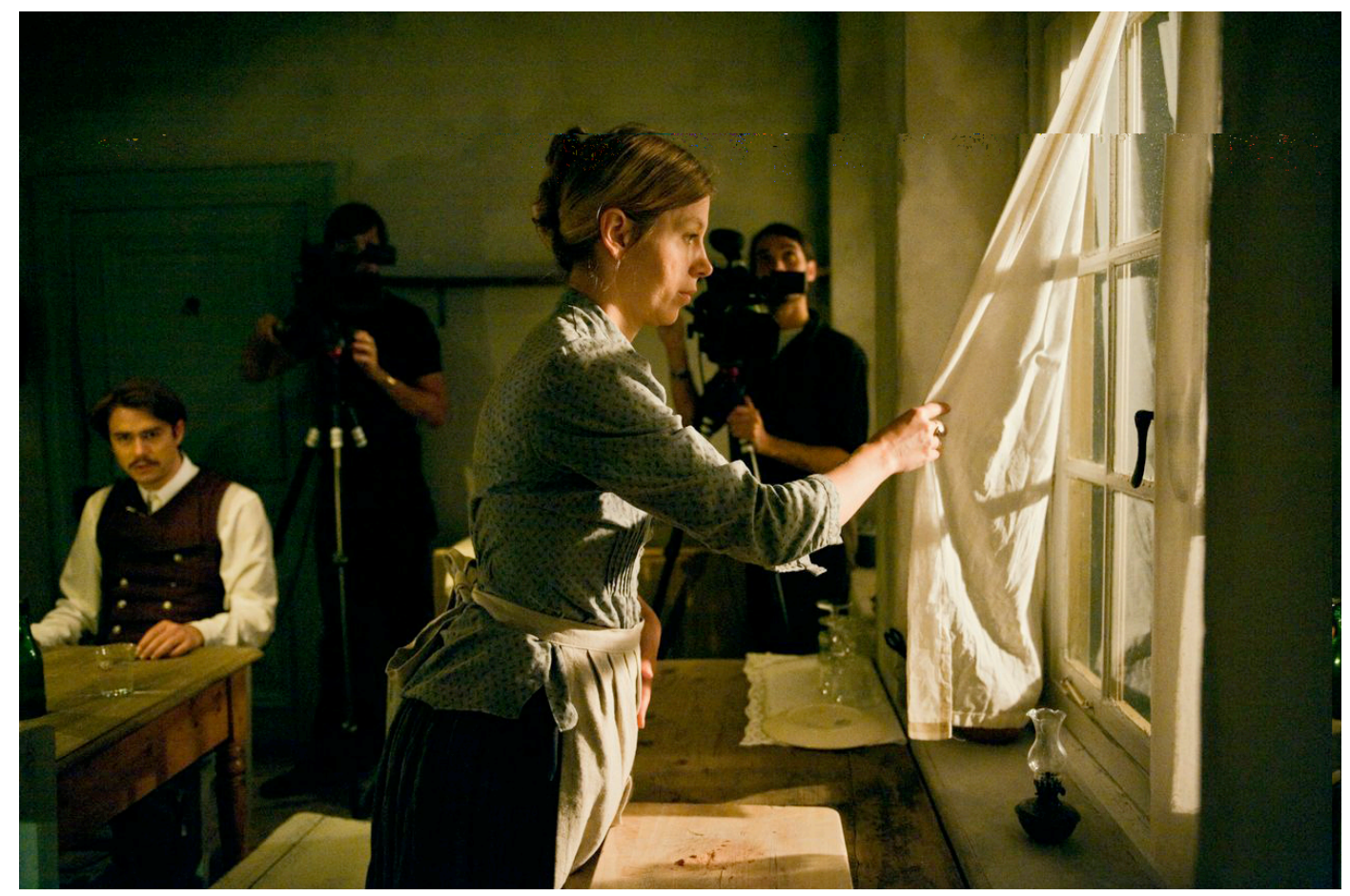

Fig. 1 Tilman Strauss, Jule Böwe, in the foreground (on the stage/film set of interior kitchen in Fräulein Julie, with) camera operators behind the actors). Barbican, 2013. Photo: Stephen Cummiskey.

The role of the sound makers/musicians is of particular interest in this constellation, if we recall that early cinematic technology - the camera as instrument of visual technology created a "silent" genre which overdetermined the kind of acting that was integrated into the film apparatus. As Marko Kostanić argues in a short but brilliant essay on the "Choreographic Unconscious," early motion pictures

irreversibly influenced theatrical gesturality and acting. Cinematic thinking first appeared at that time, meaning that films no longer functioned as a technologically facilitated way of documenting the theatrical dispositif. Apart from the theatre as an accessible method of representation, one of the reasons for the "time-lag" in the evolution of cinematic thinking was the original fascination with the invention of the medium. The discovery of motion pictures resulted in an inevitable desire to show as much liveliness, movement, and intensity as possible. [...]

That is the register in which the cinematic acting of the time evolved, which used a burlesque, accelerated, and caricatured variant of almost incessant theatrical gesturality in order to become equivalent in persuasiveness to the ultimate sort of newly-discovered persuasiveness - a faithful reproduction of reality. But then, primarily owing to Griffith and partly also to Kuleshov's experiment, there was a break. Using the potentials of montage and close-up made it possible to enter the hitherto inaccessible space of theatrical relations and made the previous type of gesturality and its corresponding persuasiveness obsolete. This led to a sort of repression of the actor's body and, accordingly, to the narrative relevance of 
immobility, neutrality, and the focussed body. The crucial thing was that it was no longer the movement that was choreographed on film; it was the gaze, which automatically created cinematic psychology and suspense.(12)

In the following, I will use certain terms such as "mixed reality," "montage," or "modulation" in order to develop a critical vocabulary able to do justice to the complex filmic scenography of Mitchell's directing, but also to raise questions about the extent to which the (Hitchcockian) cinematic suspense and fastidious play on the psychology of the gaze "repressing" the actor's body - work effectively on stage. The use of the close-up and what Kostanić calls the "focussed body" is certainly one of the more remarkable and also problematic features of Mitchell's Fräulein Julie. She does achieve a tranquil poetic sense of realism in the subtle foregrounding of the very creation of such close-ups, often done downstage right at a table that serves as a miniature film set for special camera takes of "mirroring" scenes enacted with and by the "Kristin double" - the actress that silently substitutes for the character of the cook in the household in Strindberg's play. The slow close-up poetic realism I detect reflects a similarity to the long shot in Tarkovsky's films, and thus the narrative relevance of immobility and neutrality for the acting in theatre poses itself as one of the main questions. Contrary to what Mitchell seems to believe when she asks her actors to step inside the shot to "behave accurately," it is the camera that acts accurately to frame the behavior and compose the emotional affect. Another question might be whether the camera-driven live film theatre can generate "automatic" suspense if in fact we become all too aware of the camera-as-actor, i.e. the camera's role as an agent of capture and the montage of expressions.

Significant here is the shift in attention and dramaturgical weight executed by Mitchell's adaptation of the script for this production (dramaturgy and translations by Maja Zade), namely moving a minor character to the center. Apparently Mitchell was drawn to what she considers "the spirit of radicalism" in Strindberg's investigation of early naturalism, paying much attention to the author's fervid responses to Zola's essay on "Naturalism in Theatre" (1888) in his own ideas on staging, set design, lighting and acting. She quotes some of Strindberg's stage directions for Fröken Julie (written in 1888) in the Program Notes as examples of remarkable formal innovations which one would have to imagine as radical in their historical context (if it were possible to do so after a century of mainstream AngloAmerican theatre culture accustomed to the new realism Strindberg's play was advocating). Mitchell admits being attracted to the idea that a theatrical revolution could be "contained 
within a lifelike rendition of banal and simple actions described in a stage direction" rather than dramatic dialogue.

Fräulein Julie's setting is the kitchen of a country mansion, where on Midsummer's Eve the daughter of the house, Miss Julie, has a sexual encounter with a servant, Jean, who is her cook's fiancé. Mitchell takes as her starting-point the stage direction for Kristin, the cook, who was the least significant of his three characters according to Strindberg, described by him as a subordinate figure "without individuality." Left in her kitchen while her fiancé, and their mistress, Fräulein Julie, join the midsummer's night festivities, Kristin must perform, Strindberg directed, "as if the actress were really alone in the place":

A schottische tune played on a violin is heard faintly in the distance. While humming the tune, Kristin clears the table after Jean, washes the plate at the kitchen table, wipes it, and puts it away in a cupboard. Then she takes off her apron, pulls out a small mirror from one of the table-drawers and leans it against the flower jar on the table; lights a tallow candle and heats a hairpin, which she uses to curl her front hair. Then she goes to the door and stands there listening. Returns to the table. Discovers the handkerchief which Miss Julie has left behind, picks it up, and smells it, spreads it out absentmindedly and begins to stretch it, smooth it, fold it up, and so forth.

[Fräulein Julie, stage direction, reprinted in Program Notes, Barbican Theatre]

Mitchell's adaptation uses Zade's translation which substantially reworks Strindberg's text changing dialogue, in some instances, into inner monologues (read out as filmic voice over by actors positioned inside small sound recording booths on either side of the stage). This technique is in keeping with Mitchell's earlier filmic productions such as The Waves (adapted from Virgina Woolf) or the 2012 Schauspielhaus Cologne staging of Reise durch die Nacht (adapted from Friederike Mayröcker's prose novella) which features the main character as a narrator of internal monologue. Mitchell thus turns Kristin's solitary reverie into the main filter through which the action of the play is mediated. Julie and Jean become the subordinate figures in this triangle.

The set construction for this filtering is crucial, as the staging attempts to design a mixed reality performance that allows the overlaying of the physical environment with the filmed screen-projections. The most fascinating aspect of this framework for an "augmented reality"(13) is the simultaneity and overall synchronicity of filmic and theatrical spaces, and 
the traversable relationships between film and physical stage reality which the audience can observe at all times. Mitchell and her co-director, Leo Warner, situate the drama in three conjoined yet separate realms: an enclosed kitchen mid-stage left (adjacent to a small sitting room, in the center, and a bedroom mid-stage right) where the audience has a partial view of the figures within; at the front of the stage, where Kristin's double appears, and on a screen above the set, where the drama is shown in live close-up, filmed by the ensemble themselves.

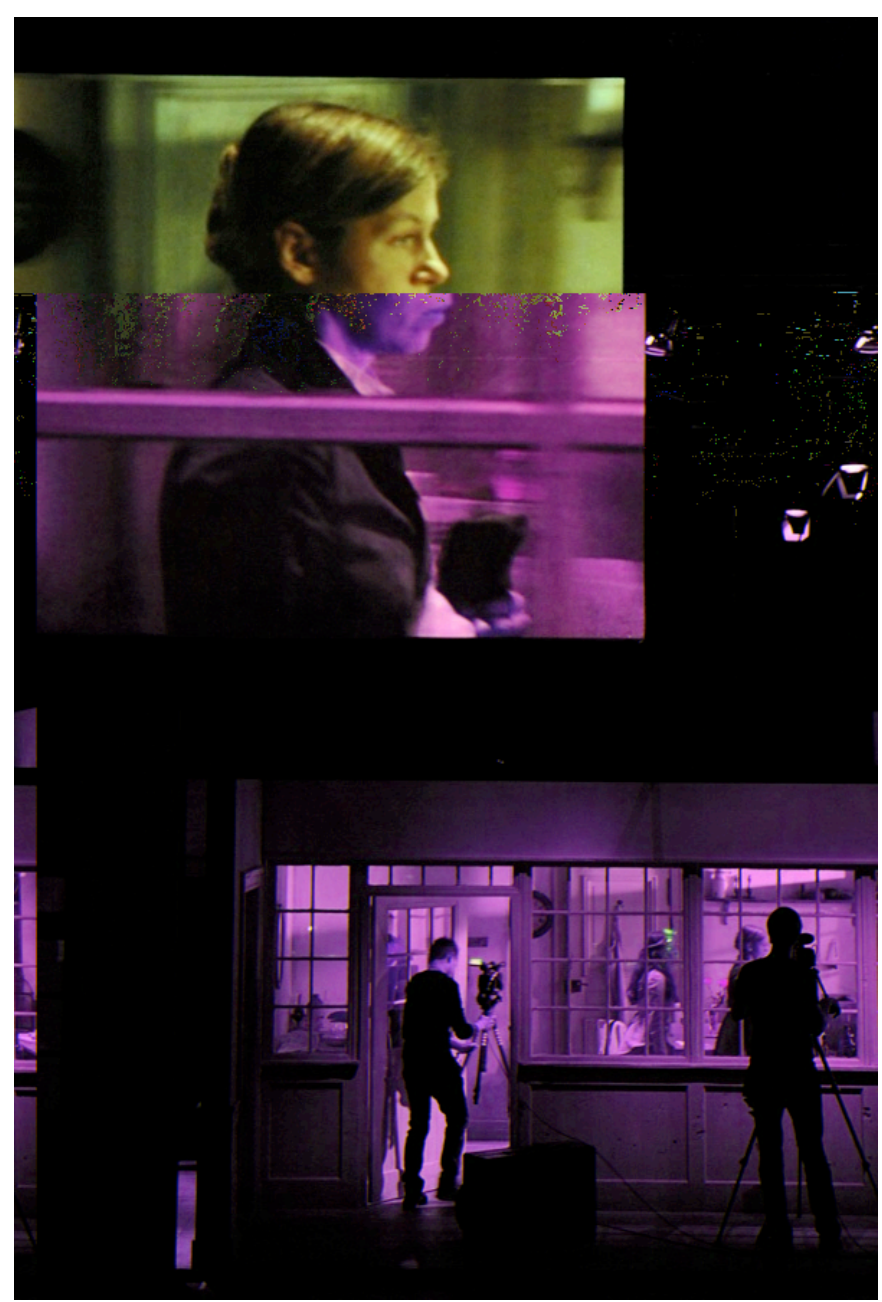

Fig. 2 Jule Böwe (on screen above the stage/film set with camera operators) in Fräulein Julie, Barbican 2013. Photo: Stephen Cummiskey

Alex Eales's set construction of the interior rooms - there is also an "exterior" space stage left used only sparsely, for example for the dance - is simple and under-stated, while the sepia-toned costumes aspire to historical accuracy and much attention is given to numerous props, mostly kitchen utensils and household items as mentioned in the stage direction above, which the actors take from a cupboard placed off-center right. 
In the opening scene, the screen hangs in front of the interior rooms before it is raised up above the set, and we watch a quiet pastoral scene of a landscape with flowers, accompanied by the cello; as the screen is raised up, our attention is drawn to the creation of the landscape: a camera has been filming a miniature "landscape set" built onto a small cardboard platform, the flowers on it are lit by a small stage lamp and we see the cameraman filming this set, behind him the cellist in the sitting room playing her instrument. Our attention is also directed to the two sound-generating members of the ensemble who had entered stage left to position themselves at a table with a vast array of tiny wooden, glass and metallic objects, jars, paper, cloth, matches, etc., which they use during the course of the performance to create the live sound for their microphones. They can watch the projected film on a small control monitor facing them on their table; there are additional closed circuit monitors in the interior set visible only to the camera operators. Like in the radio dramas of old, the sound actors create the sync-sound effects for the action we see on screen, and this begins, perplexingly, with Laura Sundermann tapping her left foot onto a floor board (equipped with contact mic) to simulate Kristin's walk around the interior kitchen set, "alone in the place" while our imagination has already been taken far afield into the midsummer eve. This impressionist play on nature and naturalism sets the tone for the production, and the presence of the cello adds to the elegiac mood evoked in my mind once the softly spoken German passages, which the London audience can read in English surtitles, begin to voice or translate Kristin's internal reflections. The cook's unseen labor is her poetry. The frequent shots of Jule Böwe 


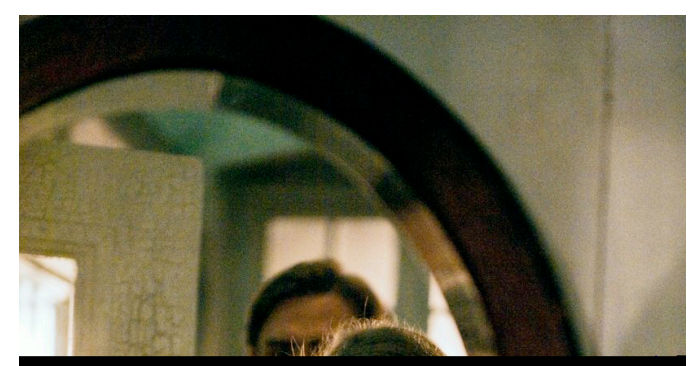

Fig. 3 Jule Böwe watching herself being watched in the mirror by Tilman Strauss in Fräulein Julie. Barbican, 2013. Photo: Stephen Cummiskey

looking into a mirror intensify the almost Bergmanesque atmosphere Mitchell achieves in her careful emphasis on the character's probing if resigned self-reflexiveness. It is this selfreflexiveness which ultimately haunts her, when she slowly realizes her entrapment and the betrayal by the callous fiancé. 


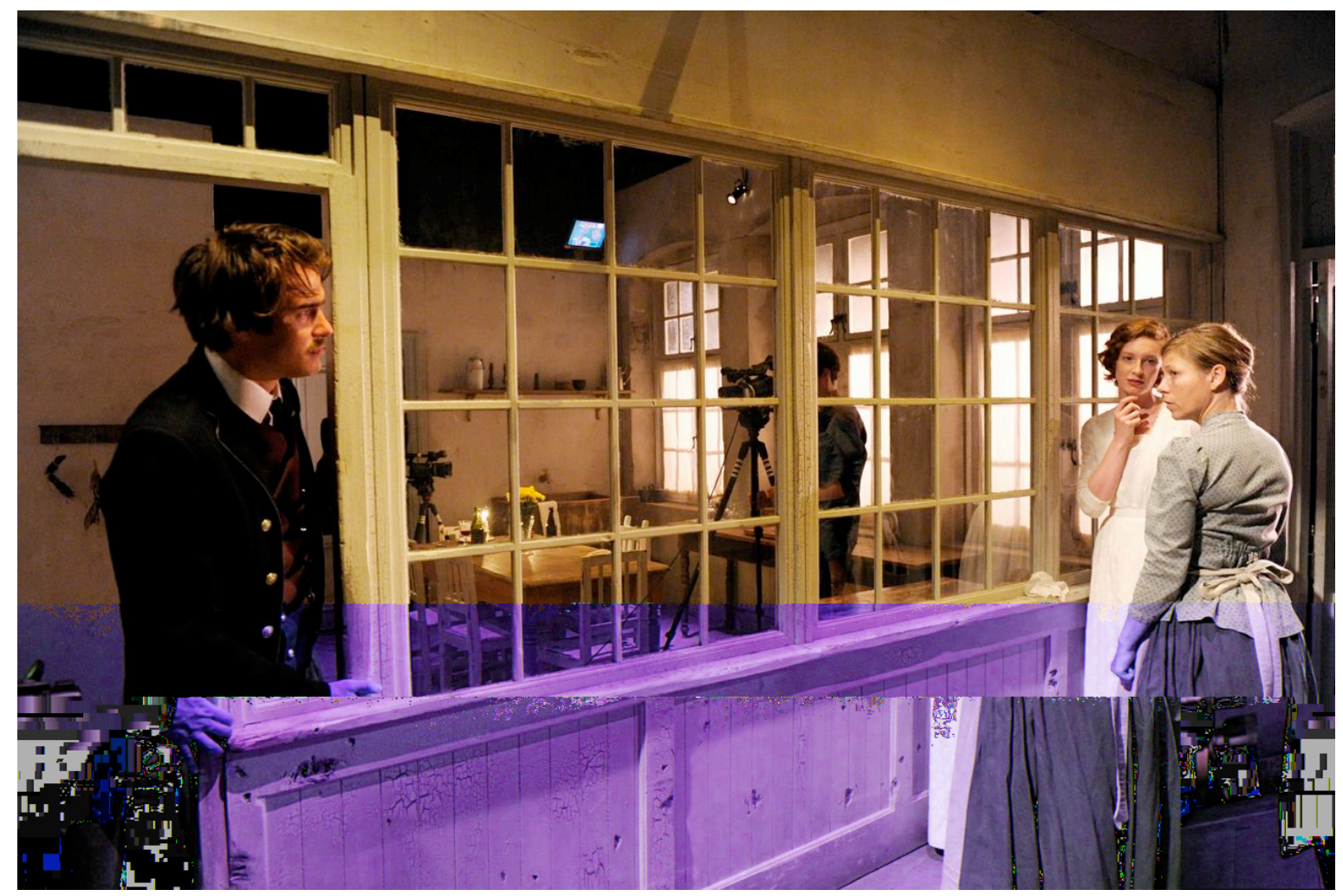

Fig. 4 Tilman Strauss, Luise Wolfram and Jule Böwe (on the stage/film set of interior kitchen in Fräulein Julie). Barbican, 2013. Photo: Thomas Aurin

It is tempting, then, to ask how the performance can maintain its psychological atmosphere of suspense, and the continuity of the implicit drama of class conflict between a mismatched couple, through a self-consciously filmic exploration of gazes (the intrigue of overhearing, overlooking, eavesdropping) and the montage of multiple angles which we in the audience experience as a paradoxical realism of emotional affect - paradoxical in the sense that we are not immersed into the make-belief of theatrical drama, action, and characterization, but asked to witness at all times the construction of a film, i.e. the artificial constructedness of each gesture, facial expression, unspoken word, glance, reaction, and anticipation in the relationships between the three characters?

One could argue there is perhaps an inevitable Brechtian Verfremdungseffekt built into Mitchell's production as it demonstrates, and thus makes explicit, the gestus of Kristin's (in)action, filmed from every angle with multiple cameras (high and low angle, over the shoulder shot, shot-reverse shot, etc), as well as doubling the actions, say of her hands, by a second address whom we have to observe re-enacting the gestus on another side of the stage (simultaneously while watching Jule Böwe, the camera operators, sound makers, and the 
resultant film scene on screen and the découpage - the edit cuts). This multi-perspectivally edited scenario of continuous montage is demanding. No illusion of realism can be sustained in this way, except if the audience were willing to immerse themselves in a virtual and poetic world not reliant on dramatic realism but a congenial acceptance of this continuously performed passage between actual, tangible and yet constructed filmic (augmented reality) space.

Strindberg's play is transformed, in this particular live film theatre version, into a constructivist set, and one wonders how Mayakovski or Brecht (and Benjamin whose writings on the apparatus of technical reproducibility might be pertinent here [14]) would have considered both the productivist and the distanciation techniques at work here, especially since Mitchell seems rather less interested in the political dimension of theatre than in the cinemato-poetic logic of her camera and framing devices and the "perception-images," as they pass from the objective to the subjective.(15) What do these constructed and complementary images (shot-reverse shot/observer-observed) makes us think or feel?

As we are not invited to identify with the characters or the fictional drama, our attention is shifted to a level of aesthetic neo-realism dependent on the production's camera (and sound effect) self-consciousness. For example, I feel an almost kinetic, choreographic delight in becoming aware of Sundermann's leg movement, as the taps with her left foot generate the sound for the walk of the actress we see on screen and below in the interior kitchen. Sundermann raises her left leg in a succinct slow motion manner, then fluidly taps down her foot and swiftly raises her leg again. She is actually expressly enacting this movement for the sound, as if framing it for an optical sound test, in the sense in which Benjamin explains the function of the camera and the audience's identification with the camera, except that this movement is not filmed but generates sound. The screen images often focus on close-ups of facial expression or the actions done with Kristin's hands - but the illusion effect of synchresis (16) is perfectly maintained throughout most of the evening, every sound on film is created by Sundermann and Nagel, with the exception of the spoken words that are captured by the five cameras or, more emphatically during the poetic inner monologues, recited by the actors in the sound booths (they wear headphones as if they were in a recording session). The production thus plays deliberately on the pretense, on the sense of ostentation or affection of an emotion. It also, in my view, refers us slyly to the characteristic procedures 


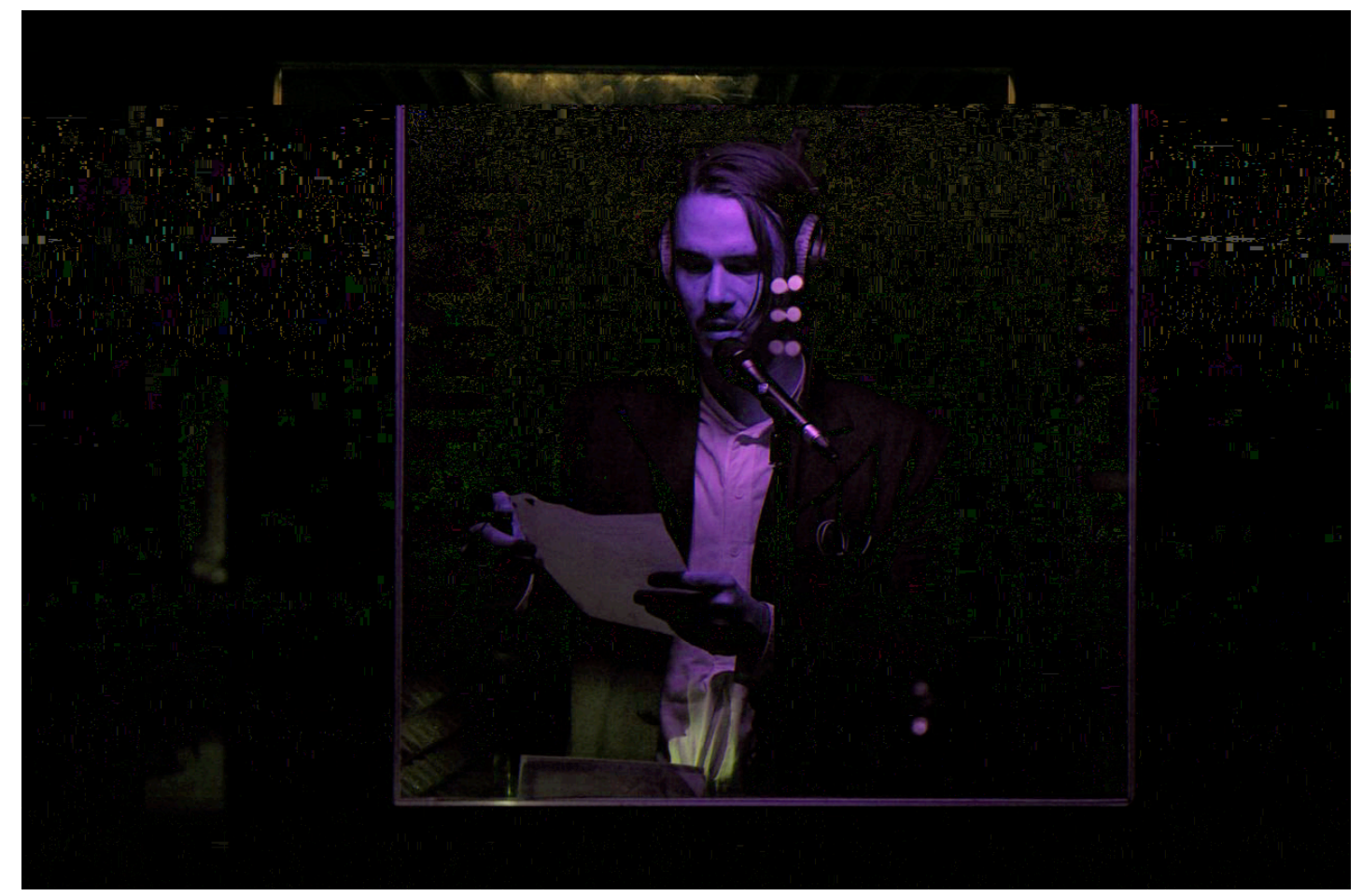

Fig. 5 Tilman Strauss during a voice recording in the sound booth in Fräulein Julie. Barbican, 2013. Photo: Stephen Cummiskey

of radio plays or sound recordings generally, and Benjamin already in 1932 notes that the (epic) theatre "is utterly matter-of-fact, not least in its attitude towards technology," adding that "its discovery and construction of gestus is nothing but a retranslation of the methods of montage - so crucial in radio and film - from a technological process to a human one.”(17) Benjamin's theory implied, back then, that radio represented an advanced technical stage: it made its technology more evident and was able to "take up" older cultural productions such as theatre (by means of adaptation), replacing it so-to-speak with a "training of critical judgement." While I do not see Mitchell's staging intending to use the montage principle of epic theatre (which is based on interruption), it does to some extent resemble what Benjamin calls the "dramatic laboratory"(18) - focusing on the theatre's unique opportunity to "construct" human behavior and action. It is this sense of constructionism that appealed to my critical judgement while watching the technical process.

We observe, again and again, the intricate passing from objective to subjective perception in the stage film (while we note the camera operators scurrying about the exterior/interior set with the tripods making sure they have set up their camera angle quickly to be on time for the montage, dragging their cables around with great dexterity). I will use two examples here. In 
the opening sequences, this play seems to become a film about a lonely servant, whose life is a series of repeated domestic tasks and whose existential thoughts are bound by quotidian work. Kristin prepares a meal of kidney for Jean; she winds up the clock; she cleans the vegetables; she tests the sharpness of a knife, and then cuts the kidneys. It is women's house work, unglamorous, often tedious, and as Strindberg noted in his stage directions, the actress need not look in the direction of the audience, she can turn her back to the public. The cameras do the work for us, they act as point of view (POV). We see what Kristin sees. The subjective image is, according to Deleuze, the thing seen by someone qualified or interior to the set: we see the knife through the eyes of Kristin. We observe the sensory, active and affective factors of her testing the knife and cutting the meat.

Unobtrusively, perhaps barely noticed by the audience, Kristin's double is enacting the same gestures downstage right at the table where the close-up of the cutting is shot, now we see the small lamp being switched on, now the camera being focussed on the table top, then the cutting - in this scene the double does not even need a camera operator, she becomes her own operator, focussing the lens on the small lit area on the table top, then proceeding to do the cut which we then see edited into screen image sequence. The camera-actor is left on its own.

In this case, Deleuze suggests, we need to think of the image as objective, "when the thing or the set are seen from the viewpoint of someone who remains external to that set." But he then goes on to say the observing and the observed can be reversible or complementary, undecidedly, for "what is to tell us that what we initially think external to a set may not turn out to belong to it?"(19) Ironically, Mitchell of course is using a double set, so to speak, downstage and center stage, and the double actresses perform the same action for us to experience as montage on screen. In regard to the close-up of the affection-image - and Deleuze immediately mentions Bergman's Persona as an exemplary, complex manifestation of the close-up being the face (turning it into a phantom - "both face and effacement") - we only see Jule Böwe's melancholic face, her silent expression (as her double, in the sound booth, reads a series of poetic lines about "Das Nachleuchten der Einsamkeit, die Spur gibt es, und die Nachwelt gibt es ...") when she looks at herself in the mirror. The double is 


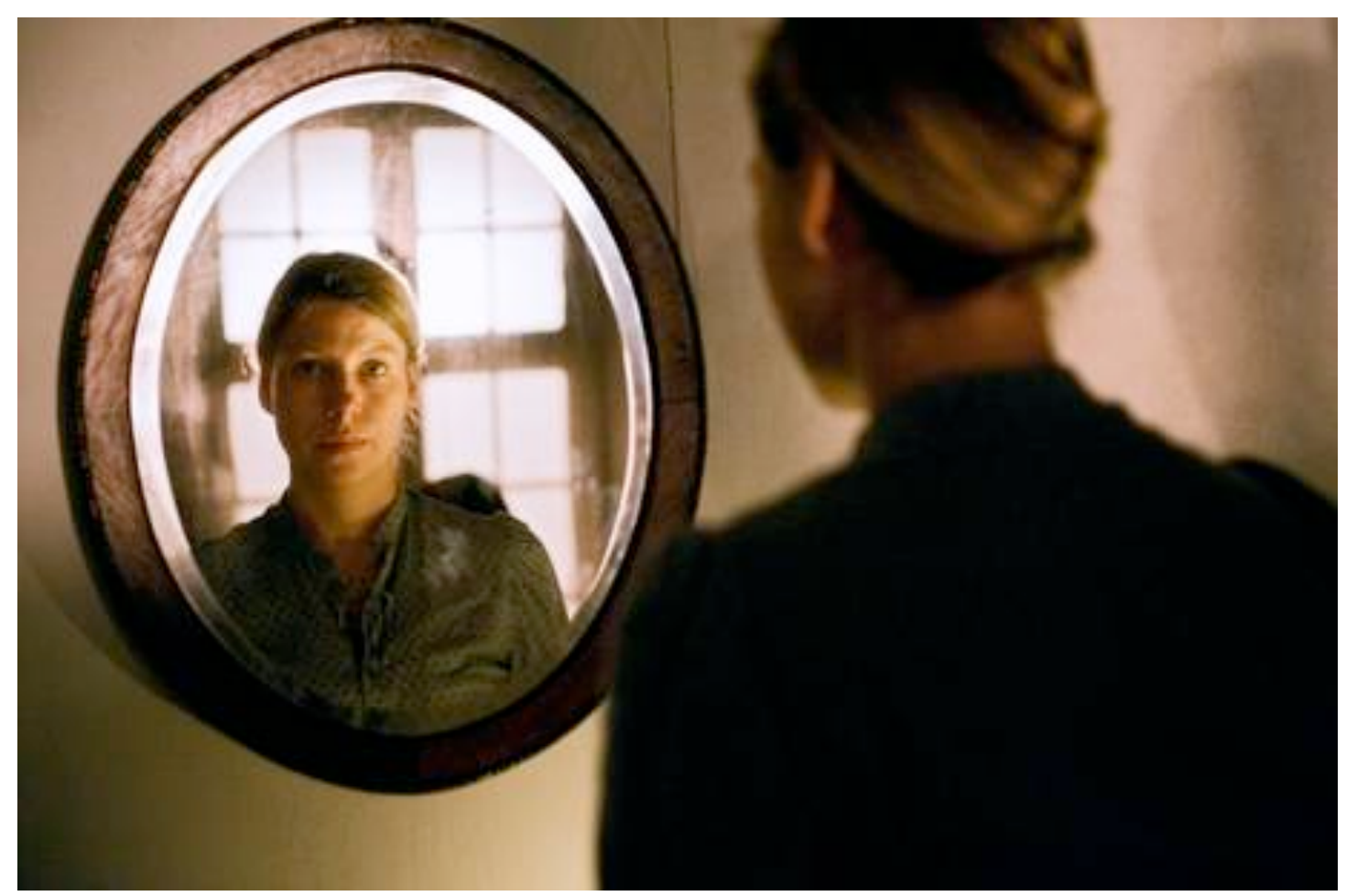

Fig. 6 Jule Böwe watching herself in the mirror in Fräulein Julie. Barbican, 2013. Photo: Stephen Cummiskey

effaced but lends Böwe's character her voice, perfectly “mismatching” (as Chion would say) the individual's voice and face, the unity of sound and image, the subjective and objective. It matches, but it is a false match. For this context of matching/synchronizing or defacing image and voice, image and soundtrack, Chion has much to say about the various possibilities of modulation between the real and the rendered, the so-called "phantom audio-visions," contradicting the "naturalist" perspective of an illusion of unity, a perspective that postulates a natural harmony between sounds and images, disturbed through almost inevitable technical falsifications in the filmmaking process that make postproduction rendering necessary and desirable (addition of sound effects, etc).(20) In Mitchell's production, the sound actors seek to stay close to a phantom "naturalism" in many of the sound effects they produce (some match precisely the action we see being created in the kitchen or the sitting room, such as the lighting of the candles Miss Julie enacts near the end, or Kristin's dressing up after the bedroom scene), but we also discover, in some moments, an even more intriguing asynchronicity (in the bedroom scene) or negative sound, when the image calls for a sound but the film does nor produce it for us to hear. 


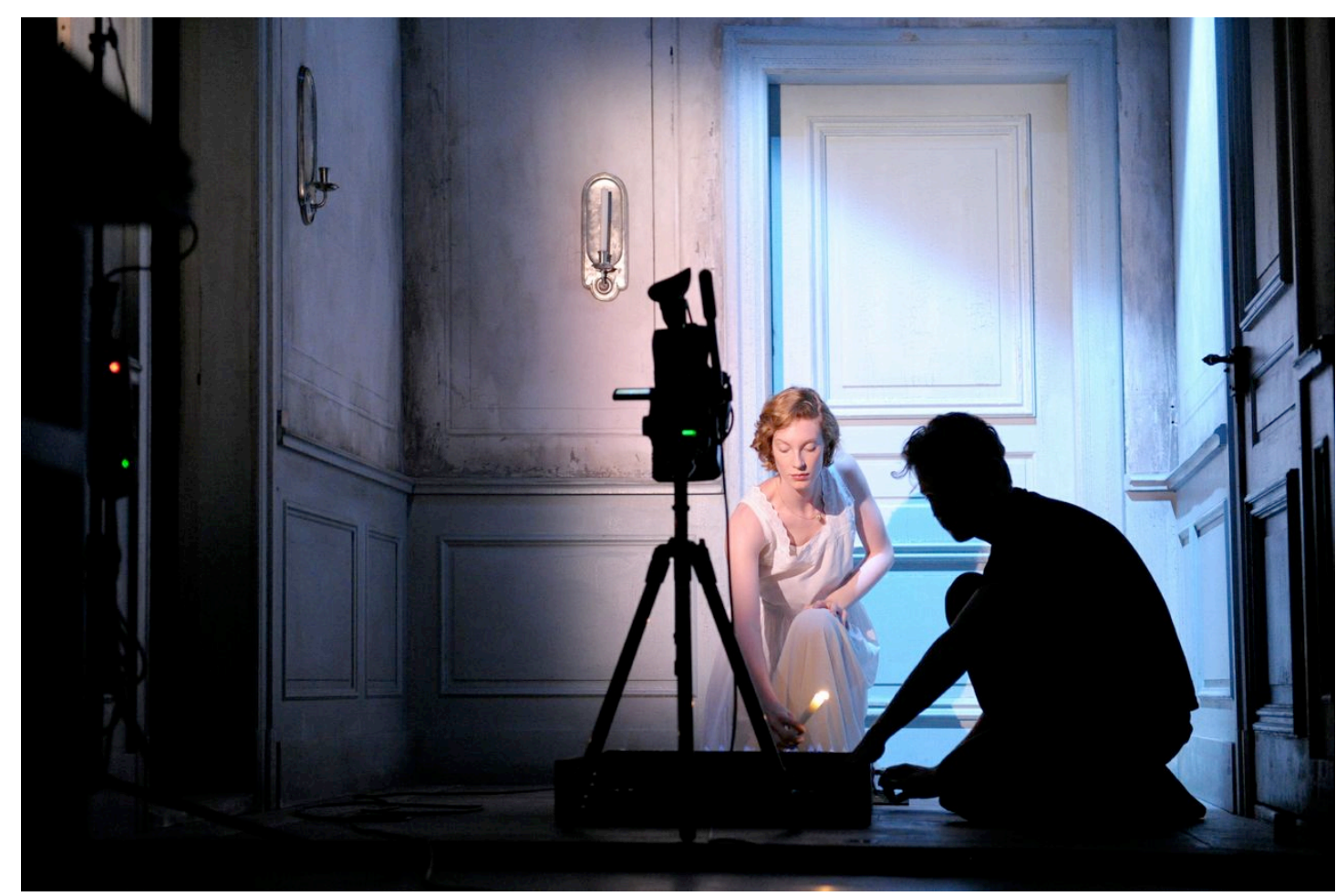

Fig. 7 Luise Wolfram, lighting candles, and camera and camera operator on the stage/film set in Fräulein Julie. Barbican, 2013 (C) Thomas Aurin

Similarly, the textual speech of the voice over, in the poetic inner monologues, does not necessarily correspond to the diegetic narrative of the images created by the actors nor reflect Strindberg's naturalism. But Mitchell directs a powerful audio-visual scene late in the performance (the bedroom scene), when Kristin wakes up at night and hears Julie's and Jean's voices in the room below. We see her in bed on screen (her body doubled by Cathlen Gawlich downstage right), then moving to the table, taking a glass and holding it to her ear, amplifying the sound of the voices (performed by Strauss and Wolfram in the sound booths), and their muffled dialogue suddenly becomes clearer. The modulation of the sound here is accomplished by the sound actors who use digital effects to achieve this image of reverberating conductivity which reflects the claustrophobic atmosphere of the triangular relationships with a rare power.

The camera work of the ensemble is outstanding throughout, the timing and precise cueing of each new camera angle and transition perfectly enacted, revealing the ease and professional comfort with which the Schaubühne ensemble approaches the multimedia mise en scène and subdued on-camera acting, perhaps not surprising given the interest German theatres have invested in deconstructivist dramaturgical visions (Frank Castorf at the Berlin Volksbühne has worked consistently with camera teams on stage to disturb any central perspective and 
illusionism; Chris Kondek has created eccentric video-theatre works at the Munich Kammerspiele and Hamburg Schauspielhaus; Hotel Modern, Rimini Protokoll and other independent companies have used intermedial staging techniques for some years on the continent).(21)

What remains to be interrogated, then, is the overall impact that augmented theatre has on our imagination, the question of how the construction of live film on stage reflects the play of gazes instrumental for its psychological dramatization of the character's relationships of entrapment, and how the use of digital modulation in real-time sustains or enhances the perceptional complexity posited by the multiple camera angles. The proscenium stage conventionally does not offer a multi-perspectival experience as it can be achieved in installations or processional/site-specific performances enabling audiences to choose variable points of attention. The Barbican stage is a proscenium stage, and thus the fragmentation of viewpoints has to be produced through the complex mise en scène of multiple simultaneous spaces and the shifting roles of the actors or inter-actors who fluidly exchange activities (character, camera person, sound maker, voice-over reciter, prop person, lighting technician, etc). This mosaic quality offers a rich palette of modulations affecting the entire spatiotemporal organization of live film in the theatre. Mitchell stays with a cinematographic framework not attempting more advanced computational interactivity as we have seen it in

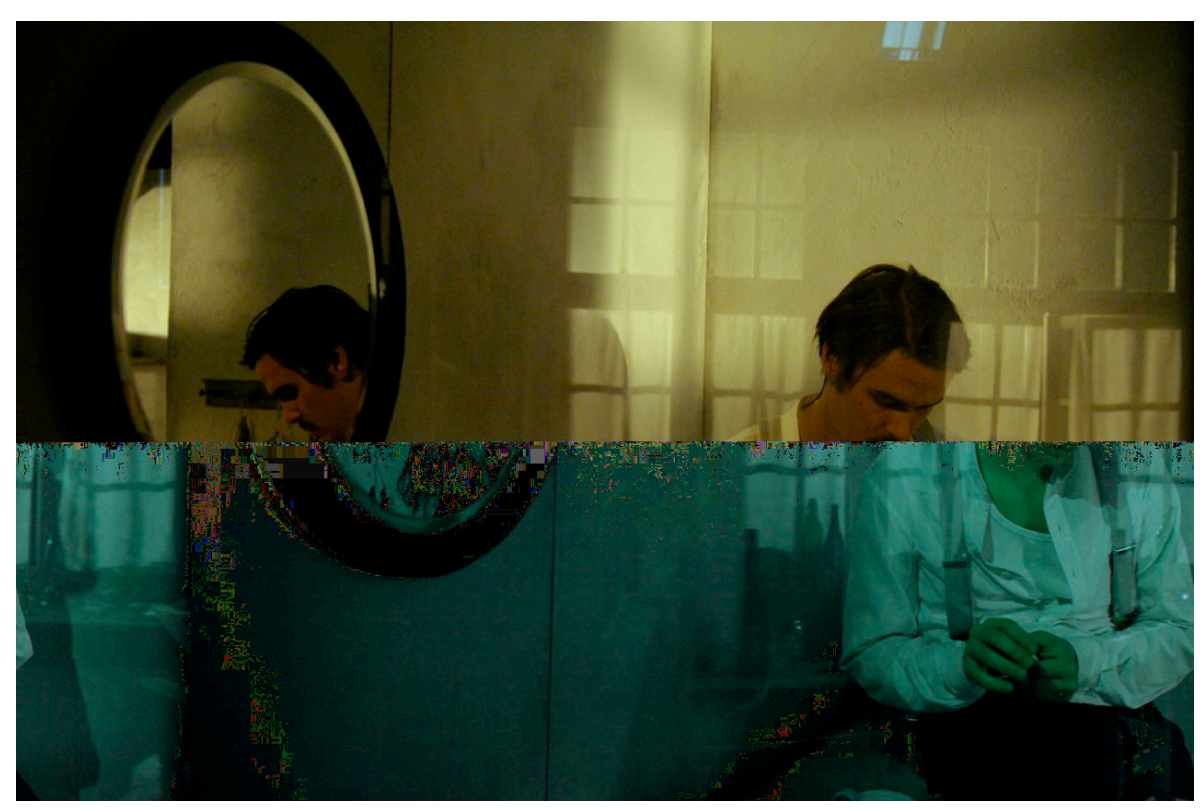

Fig. 8 Tilman Strauss reflected in the mirror in Fräulein Julie. Barbican, 2013. Photo: Stephen Cummiskey 
dance. Clearly, contemporary dance/technology productions use the apparatus differently, focusing more intrinsically on movement and the many possibilities of motion graphics and digital animation, thus remaining - if we follow Kostanić's analysis - indebted to the sensory-motor gesturality of the movement-image and its accelerations and decelerations. Chunky Move's Glow (on tour between 2006-08) and Mortal Engine (shown at Southbank Center, 2012), or Wayne McGregor/Random Dance's recent Atomos (shown at Sadler's Wells, 2013), are good examples of this. On the kinetic level, Fräulein Julie offers no suspense at all. In light of my references to dance, she also does not seem interested in exploring the encounter between image and body and how movement or behavior might be affected by the technological agent.

Mitchell's take on Strindberg's early naturalism transposes Fräulein Julie into a form of poetic neo-realism reliant on "purely optical and sound situations" which Deleuze associates with the transition from early cinema (movement-image based) to neo-realist cinema (timeimage based).(22) Deleuze describes a scene from De Sica's Umberto $D$ that exemplifies a focus on the eyes and the gaze, mentioning the young maid in the film going into the kitchen, making a series of mechanical, weary gestures, cleaning a bit, driving the ants away from the water fountain, picking up the coffee grinder, stretching out her foot close to the door with her toe; then her eyes meet her pregnant belly. Deleuze proceeds to argue that De Sica, Rosselini, Antonioni, Visconti, and later Truffaut and Hitchcock, were moving beyond the action-image of the old realism, focussing instead on optical situations of tactile images and sound, images of time and contemplation. With Hitchcock and later filmmakers, the emphasis shifted increasingly toward the "indiscernibility of the actual and the virtual," the real and the imaginary - the physical and the mental folded into each other.(23)

While the visionary aesthetics of Visconti or Tarkovsky are incontrovertibly powerful instances of the history of film, and Hitchcock's mastery of psychological suspense crystallizes the mirror effect of cinema - the double of the mental image including the spectator into the vertigo of the film (the viewer, as the protagonist of Rear Window, is immobilized in the gaze) - the theatre audience is not glued into the screen in the same way. The audience is not fully in-cluded, so to speak, in the thought-montage but reminded, at all times, of the construction carried out, the cut, the positioning of the camera angle right there in front of us, on this darkened stage, so that we can see Kristin's gaze and her growing suspicion of Jean and Julie on screen as we look up. We look up and down, down and up. We 
are neither immobilized nor trained to be critical and pressed into seeing our political concerns (Benjamin). Nor do we care about the frequent gazes into the mirror, since we hardly ever find out anything about Julie's or Jean's desires or motivations. We are a little bit lost in translation. We are aware of the differentials between stage and screen and also their intermediate flow, and while this is hardly Strindberg's idea of naturalism, what distinguishes Mitchell's work is her insistence on a steady, quiet and consistent aesthetic of poetic realism that will be intriguing to some, and impressive to most (who cannot avoid admiring the stage craft). But it may surely be off-putting to others who recognize the repression and effacement of physical, energetic and political theatre, and the hypermediated contrivance of a multiperspectival scenography that feels emotionally cold, removed, inconsequential. These acting bodies do not resonate.

While Mitchell's lack of concern for acting might be acceptable or even commonplace in the context of postdramatic theatre, it appears contradictory given her expressed interest in psychological realism and human behavior, and her hope that the images "crystallize the inner landscape of the characters' feelings" (as she states in the interviews). Her choice of adaptation also remains a puzzle, as her complicated staging of the gaze, with the filmic techniques she involves so comprehensively and competently, does not quite succeed in raising the Strindberg narrative or the performance to the level of cinematic suspense or complexity audiences are accustomed to from Buñuel, Chabrol, Truffaut or Scorsese or any of the contemporary filmmakers (e.g. Wes Anderson, David Lynch, but also Lars von Trier and Dogme95-influenced handheld cinematography) following in the footsteps of Hitchcock's realization of deep and irrational disturbances of the unconscious. And unlike, say, Marguerite Duras (in India Song), Mitchell never really bothers to interrogate the potential disconnection between sound and image, the irrational cut between the two.

Thus her live theatre film weakens the theatricality of the physical body without inventing, in her modulations of the mixed reality of augmented theatre, a critical exploration of the construction of sound framing, and alignment of her images. She claims that there "always will be errors since it is all live," as she says in the interview with Mark Kermode, but I did not notice any glitches, slippages and breaks in the continuity to stimulate my imagination and illuminate the pressing question of how images can be actionable and disrupt the habituation of the sensory apparatus to technological artifice. Even more noticeable, however, 
is the paradoxically damaging effect of her intermedial strategy: by dispossessing the live theatre of some of its particular strengths of physical, emotional, kinetic energies and resonances, at the same time she cannot achieve the uniquely "focussed" body (Kostanić) of cinematography as we are not watching the screenic image alone, in this constructivist production, but the projection of its weakened, eviscerated double on a cluttered proscenium stage. If she wanted to make the chaos of the clutter evocative of a certain incompatibility between technology and physical behavior, I would have liked to experience it in ways that are not at all familiar to me from the movies, nor from the theatre.

Note:

Fräulein Julie (after August Strindberg), a Schaubühne Berlin production directed by Katie Mitchell and Leo Warner, was presented at the Barbican, London, April 30 - May 4, 2013.

\section{References}

(1) Alan Ackerman/Martin Pucher, eds., Against Theatre: Creative Destructions on the Modernist Stage, Basingstoke: Palgrave Macmillan, 2006, p. 9. See especially, Charlie Keil, “'All the Frame's a Stage': (Anti-)Theatricality and Cinematic Modernism," pp. 76-91.

(2) Cf. Peggy Phelan, Unmarked: The Politics of Performance, London: Routledge, 1993; Philip Auslander, Liveness: Performance in a Mediatized Culture, $2^{\text {nd }}$ edn, London: Routledge, 2008; a careful summary of the antagonistic debate is offered by Steve Dixon, Digital Performance: A History of New Media in Theater, Dance, Performance Art, and Installation, Cambridge, MA: MIT Press, 2007, pp. 115-34.

(3) Antonin Artaud, The Theatre and its Double, trans. Victor Corti, Richmond: One World Classics, 2010, p. 47. Unlike M.C. Richards' first translation for Grove Press (1958), Corti uses "wholly substantiated attraction," which of course resonates with Tretyakov's "theatre of attractions" and Eisenstein's "montage of attractions." For a fascinating commentary on the Russian theatre/film avant-garde, which has inspired the current dance rehearsals of the DAP-Lab, see Gerald Raunig, A Thousand Machines, Cambridge, MA: MIT Press, 2010.

(4) See his chapter "On the Balinese Theatre," esp. pp. 40-41. While working on revisions for this essay, I came across an inspiring evocation of Artaud's writings by the late Herbert Blau: "Performing in the Chaosmos: Farts, Follicles, Mathematics and Delirium in Deleuze," in Deleuze and Performance, ed. Laura Cull, Edinburgh: Edinburgh University Press, 2009, pp. 22-34.

(5) Artaud, p. 60.

(6) Artaud's notion of a "raw cinema," according to Stephen Barber, concerns the violent and disruptive unleashing of the spectator's senses experienced in the body's projection; see his 
The Screaming Body: Antonin Artaud - Film Projects, Drawings and Sound Recordings, Creation Books, 1999, p. 26.

(7) Cf. Johannes Birringer, Theatre, Theory Postmodernism, Bloomington: Indiana University Press, 1989, and Media and Performance: Along the Border, Baltimore: Johns Hopkins University Press, 1998.

(8) See Katie Mitchell's interviews with Mark Kermode on the BBC Culture Show (29 July 2008), with Dan Rabellato at the public platform show (National Theatre, 12 August 2008), and her comments on several short films by Pinny Grylls, e.g.

http://www.nationaltheatre.org.uk/video/katie-mitchell-on-pains-of-youth; http://www.nationaltheatre.org.uk/video/cinematography-in-a-multimedia-production; http://www.nationaltheatre.org.uk/video/exploring-multimedia-in-katie-mitchellsproductions. I should add that obviously in the current context the references to cinematography are no longer to celluloid film but digital moving-image technologies.

(9) Cf. Alexis Soloski, “A Double Dose of Chekhov,” The New York Times, 5 January 2014: http://www.nytimes.com/2014/01/06/theater/jay-scheib-stages-platonov-or-thedisinherited.html?_r=0.

(10) My underlying allusion is to the title of Mitchell's latest production to date, Alles Weitere kennen Sie aus dem Kino (based on a script by Douglas Crimp adapted from Euripides' The Phoenician Women), created for Schauspielhaus Hamburg in November 2013.

(11) This description is by Goebbels himself (from the program issued at the work's presentation at Ambika P3, London, 2012). See my "Choreographic Objects: Stifters Dinge," Body, Space and Technology 11:02: http://people.brunel.ac.uk/bst/vol1102/. The musicalization of scenography/choreography is a fascinating subject that could be traced from Wagner to the futurists, constructivists and later experiments in performance art following Cage, Fluxus, the Judson Dance Theatre and E.A.T. (Rauschenberg's and Klüver's 9 Evenings of Theatre and Engineering, 1966). The term "composed theatre" has been put to interesting use in Matthias Rebstock's and David Roesner's new book, Composed Theatre: Aesthetics, Practices, Processes, Bristol: Intellect, 2012.

(12) Marko Kostanić, "The Choreographic Unconscious: Dance and Suspense," in SemiInterpretations, or how to explain contemporary dance to an undead hare, BADco. program, Zagreb 2012. BADco.'s political and dramaturgical interventions into the relations of performance and image are of significance here; during a recent workshop in Zagreb (2012), we had a prolonged discussion about the "responsibility for things seen" and the "actionable image," i.e. the question whether images can have agency. I am redirecting the question here to the role of agency of the camera in generative live processing of images.

(13) See, for example, the helpful introduction to the nature of augmented theatre and various interleaved trajectories through hybrid structures of real/virtual space, time, interfaces and roles in Steve Benford and Gabriella Giannachi, Performing Mixed Reality, Cambridge, MA: MIT Press, 2011, pp. 2-3. See also, Kaisu Koski, Augmented Theatre, Entschede: Ipskamp, 2007. Mitchell's book, The Director's Craft: A Handbook for the Theatre, London: Routledge, 2009, contains only three pages (pp. 90-92) on the use of video in theater, claiming, astonishingly, that the use of video in mainstream theater is still in its infancy. 
(14) Walter Benjamin, "The Work of Art in the Age of Technological Reproducibilty" (1939), in Selected Writings, Volume 4, 1938-1940, eds Howard Eiland and Michael W. Jennings, Cambridge, MA: Belknap Press of Harvard University Press, 2003, pp. 251-83 (available at: http://evans-experientialism.freewebspace.com/benjamin.htm). I am particularly thinking of the passages (Section VIII) in which Benjamin discusses the actor being subjected to "optical tests" and the audience becoming critics of these optical tests:

"The recording apparatus that brings film actor's performance to the public need not respect the performance as an integral whole. Guided by the cameraman, the camera continually changes its position with respect to the performance. The sequence of positional views which the editor composes from the material supplied him constitutes the completed film. It comprises a certain number of movements, of various kinds and duration, which must be apprehended as such through the camera, not to mention special camera angles, close-ups, and so on. Hence, the performance of the actor is subjected to a series of optical tests. This is the first consequence of the fact that the actor's performance is presented by means of a camera. The second consequence is that the film actor lacks the opportunity of the stage actor to adjust to the audience during his performance, since he does not present his performance to the audience in person. This permits the audience to take the position of a critic, without experiencing any personal contact with the actor. The audience's empathy with the actor is really an empathy with the camera. Consequently, the audience takes the position of the camera; its approach is that of testing" (pp. 259-60).

(15) Cf. Gilles Deleuze, Cinema 1: The Movement Image, trans. Hugh Tomlinson and Barbara Habberjam, London: The Athlone Press, 1986, pp. 73-75. Deleuze points out that a film is never made up of a single kind of image but of combinations, of the inter-assemblage of movement-images, perception-images, affection-images, and action-images; his philosophy of the principal types of image movement (expanded in the second volume, Cinema 2: The Time Image) is too complex to be summarized here but individual sections in Cinema 1 on montage and especially on facial close-ups provide a thought-provoking context for a reading of Mitchell's live film staging.

(16) Michel Chion defines synchresis as the "spontaneous and irresistible weld produced between a particular auditory phenomenon and visual phenomenon when they occur at the same time," but he also addresses the many instances of elasticity in film when patterns of synchronization or negative and offstage sounds - and the whole acousmatic dimension of non-diegetic sound effects and layerings (not accompanied by the sight of a sound's source of cause). See Michel Chion [1990], Audio-Vision: Sound on Screen. Trans. Claudia Gorbman, New York: Columbia University Press, 1994, pp. 63ff.

(17) Walter Benjamin, "Theatre and Radio" (1932), in Selected Writings, Volume 2, 19271934, eds Michael W. Jennings, Howard Eiland, and Gary Smith, Cambridge, MA: Belknap Press of Harvard University Press, 1999, p. 584.

(18) Ibid., p. 585.

(19) Deleuze, Cinema 1, pp. 73-74.

(20) Chion, Audio-Vision, pp. 95ff.

(21) For further context on intermedial productions in Germany, see the special sections on "Theater und Video" in Theater Heute (April 2004), pp. 18-31, and on "Kunst, Bühne \& 
Videotapes" in Theater Heute (August/September 2007), pp. 4-31, the latter dedicated to Kondek and the late Christoph Schlingensief.

(22) Cf. Deleuze's opening chapter "Beyond the Movement-Image" in Cinema 2: The Time Image, trans. Hugh Tomlinson and Robert Galeta, London: The Athlone Press 1989, pp. 123.

(23) Ibid., p. 85. 